\title{
THE EFFECT OF TOPICAL APPLICATION OF TWO RE- MINERALIZNIG PASTES ON DENTAL ENAMEL EXPOSED TO FARCOLIN, FARCOSOLVIN AND HAEMOJET ORAL MEDICINES
}

\author{
Abeer Mostafa Abdellatif*, Rizk Abd Alla El Agamy* and Nada Mohamed Abdel Kader*
}

\begin{abstract}
Objectives: The aim of the present in vitro study was to evaluate the effect of "Casein phosphopeptide amorphous calcium phosphate" (MI) and "Casein phosphopeptide amorphous calcium phosphate with fluoride" (MI plus) pastes on dental enamel exposed to three different oral pediatric medications using Vickers microhardness test and scanning electron microscope (SEM).

Methods: One hundred extracted caries free human permanent teeth were selected and divided into three groups: group I "control group" untreated teeth; group II "medication group" subjected to oral pediatric medications Farcolin, Farcosolvin and Heamojet ; group III "treatment group" was treated with remineralizing pastes MI and MI plus after exposure to the different medications. Microhardness values were registered and selected specimens were imaged by SEM.
\end{abstract}

Results: There was a statistically significant difference $(\mathrm{P}<0.01)$ in microhardness values registered between control group (group I) and medication group (group II) and also between medication group (group II) and treatment group (group III). Images of SEM showed demineralization after usage of pediatric medications and remineralization after usage of remineralizing pastes.

Conclusions: The used oral pediatric medications had an erosive effect on the enamel surface, also in an in vitro model the use of a CPP-ACP and CPP-APF pastes had a protective effect on the demineralization of enamel.

\section{INTRODUCTION}

"Dental erosion" can be defined as a localized loss of the tooth surface without the involvement of bacteria by a chemical process of acidic dissolution $^{(\mathbf{1}, 2)}$. There is a continuous demineralization and remineralization of the tooth structure in the oral environment. Demineralization occurs if this balance is interrupted causing a progressive deterioration of the tooth structure ${ }^{(3,4)}$.

When the $\mathrm{pH}$ in the oral cavity becomes lower than 5.5, demineralization occurs, "calcium" $\left(\mathrm{Ca}^{2+}\right)$ and "phosphate" $\left(\mathrm{PO}^{4-}\right)$ ions will be allowed to diffuse from the surface of the tooth. The level of damage to the tooth substance can be influenced by

* Pediatric Dentistry Department, Faculty of Dentistry, Mansoura University 
the frequency and duration of the acid challenge. It should be noted that, there is a probability of arresting or reversing the lesion when the surface remains partially intact ${ }^{(5)}$.

Acids which may lead to dental demineralization might be external or natural in source. Common acid sources originate from the eating regimen, medicines, occupational exposure and way of life exercises (6). Dietary acids are the most widely contemplated etiological agents and can be said to be the most vital extraneous variable ${ }^{(1)}$.

"Liquid oral medications" are usually prescribed for children with a compliance to help them. For drug dispersion, physiological compatibility insurance, maintenance of chemical stability and to improve flavor, "acidic preparations" are frequently vital ${ }^{(7,8)}$. The hazard of "medication-induced dental erosion" may be expanded by different factors in addition to the acidic components like frequent and prolonged ingestion, between meals and sleep time utilization and collateral impact of diminished salivary stream with high viscosity ${ }^{(9)}$. Salbutamol sulfate "antiasthmatic drug", ferrous sulfate "anemic drug" and guaifensien "cough drug" are the most generally utilized examples of these oral medicines.

It is desirable to create successful preventive techniques to manage tooth erosion as it is not always practical to eliminate the cause of tooth erosion in individuals ${ }^{(\mathbf{1 0})}$. There is a scope for agents which may be used to enhance remineralization. This has redirected researches to create novel preventive agents ${ }^{(11)}$.

Nowadays, dairy products "milk, milk concentrates and cheeses" because of their anticariogenic effect in human and animal in situ caries models have gotten a considerable measure of consideration. The protective effect of these dairy products may be due to the "phosphoprotein casein" and " $\mathrm{CaPO}^{4}$ " contents ${ }^{(\mathbf{1 2})}$.
The significant deficiency of presently accessible anti caries product is the fact that their ability to remineralize tooth surface is constrained by the low concentration of $\mathrm{Ca}^{2+}$ and $\mathrm{PO}^{4-}$ ions available in saliva. This has prompted the examination of numerous materials that can provide essential elements for remineralization. "Casein phosphopeptide amorphous calcium phosphate" (CPP-ACP) is one of the novel calcium phosphate remineralization technology ${ }^{(13)}$.

Therefore, the idea of this research was created due to the increased and prolonged utilization period of "liquid oral medicines" by children nowadays. Hence, it is worthy to further study the effect of oral medicines on dental enamel and the treatment of their effects by one of the new remineralizing products in the dental market.

\section{MATERIALS AND METHODS}

\section{The sample}

One hundred sound freshly extracted human permanent posterior teeth were utilized in this study. Teeth were gathered from healthy individuals due to periodontal disease and for orthodontic treatment according to a protocol approved by the Ethical Committee of Mansoura University. The teeth were stored in $10 \%$ thymol solution ${ }^{(14)}$ until specimens preparation and then the specimens were stored in distilled water ${ }^{(15)}$.

\section{Specimen preparations}

First, the teeth crowns were separated from their roots and then the teeth crown were longitudinally sectioned under a water cooling system in mesiodistal direction into buccal and lingual halves with a "low speed dual face diamond disc". A total 200 buccal and lingual specimens was obtained from 100 teeth. Then, the specimens were subjected to serial grinding with abrasive paper size 800, 1000, 1200, 1500 and 2000 respectively (3M Ind. \& Com. Ltda; St Paul, MN, USA) to obtain smooth flat buccal and lingual enamel surfaces ${ }^{(16)}$. 


\section{Study design:}

The selected specimens ( $\mathrm{n}=200)$ were randomly divided into three unequal different groups as follow:

\section{Group I: "Control Group”}

This group composed of 20 specimens free of any treatment and stored in distilled water at room temperature until subjected to Vickers microhardness test. Selected 5 specimens were examined by SEM.

\section{Group II: “Medication Group”}

This group composed of 60 specimens and subdivided randomly into 3 equal subgroups $(n=20)$ according to type of medication used.

Subgroup IIA: Specimens were subjected to Farcolin.

Subgroup IIB: Specimens were subjected to Farcosolvin.

Subgroup IIC: Specimens were subjected to Haemojet.

Specimens of each subgroup were immersed in $10 \mathrm{ml}$ of its respective medicine in a glass container for 5 minutes three times daily for a period of one month. Between the immersion cycles of each medicine, the specimens were stored in distilled water. The three medicines and distilled water were changed every day. Then, the specimens of each subgroup subjected to Vickers microhardnes test and selected 5 specimens from each subgroup were examined by SEM.

\section{Group III: (Treatment Group)}

This group was composed of 120 specimens and subdivided equally into 3 subgroups (IIIA, IIIB, IIIC) according to type of medicine $(n=40)$. Each subgroup was subjected to one of three medications (Farcolin, Farcosolvin and Haemojet) as in Group II for one month. Then, the specimens of each subgroup were rinsed thoroughly with distilled water and carefully dried utilizing a paper towel.
The specimens of each subgroup were divided into two equal subgroups $(n=20)$ according to the type of treatment agent used as follow:

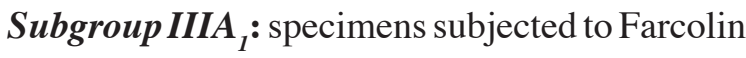
and treated with MI paste.

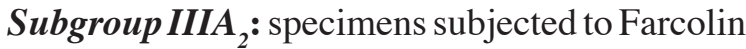
and treated with MI plus paste.

Subgroup $\boldsymbol{I I I}_{1:}$ specimens subjected to Farcosolvin and treated with MI paste.

Subgroup IIIB: specimens subjected to Farcosolvin and treated with MI plus paste.

Subgroup IIIC : specimens subjected to Heamojet and treated with MI paste.

Subgroup IIIC $_{2}$ : specimens subjected to Heamojet and treated with MI plus paste.

Specimens of each sub group were treated with a thin film of its treatment paste (CPP-ACP "MI" or CPP-ACPF "MI plus") that was rubbed with a gloved finger then kept in distilled water and any remnant of the paste removed with cotton tips before the next application. This was done twice daily for one month. The specimens of each subgroup were subjected to Vickers microhardnes test and selected 5 specimens from each subgroup were examined by SEM.

\section{Buffering capacity and pH measure:}

By using a "pH meter" the $\mathrm{pH}$ value of the medicine utilized for the immersion cycles and the "titratable acidity" which is the amount of base required to raise the $\mathrm{pH}$ to 7.0 were measured. To quantify "titratable acidity", $20 \mathrm{~g}$ of Farcolin, Farcosolvin and Heamojet was titrated with 0.5 "M KOH" in $0.02-\mathrm{mL}$ increments at $25^{\circ} \mathrm{C}$. By the following equation: " $\beta=\Delta \mathrm{C} / \Delta \mathrm{pH}$ " the "buffering capacity" $(\beta)$ was calculated in which " $\Delta C$ " is the amount of base utilized and " $\Delta \mathrm{pH}$ " is the change in $\mathrm{pH}$ brought on by the addition of the base ${ }^{(14,17)}$.

\section{Statistical analysis}

Data were collected, tabulated and statistically analyzed using SPSS (statistical package for social science) version 20. Variables were persecuted as 
mean $\pm \mathrm{SD}$. Student $t$ test and one way ANOVA were used for comparison between different subgroups to investigate any significant difference $(\mathrm{p}<0.05)$.

\section{RESULT}

\section{Microhardness results}

The mean surface microhardness of group I (control group) was $282.2 \pm 28.1$, while for subgroups IIA (Farcolin), IIB (Farcosolvin) and IIC (Hemojet) were $156.3 \pm 25.8,174.3 \pm 20.6,235.3 \pm 26.3$ respectively. There was a "highly statistical significant difference" between them. The mean surface microhardness of subgroup IIA (Farcolin) was 156.3 \pm 25.8 , while for subgroups IIIA $_{1}$ and IIIA were $288.8 \pm 15.4,307.1 \pm 14.5$ respectively. There was "a highly statistical significant difference" between them. Also the mean of subgroup IIB (Farcosolvin) was $174.3 \pm 20.6$, while for subgroups IIIB $_{1}$ and $\mathrm{IIIB}_{2}$ were $267.7 \pm 16.1,314.1 \pm 15.9$ respectively. There was a "highly statistical significant difference" between them. On the other hand the mean of subgroup IIC was $235.3 \pm 26.3$, while for subgroups IIIC ${ }_{1}$ and subgroup IIIC $_{2}$ were $256.2 \pm 22.1$, $257.5 \pm 23.5$ respectively. There was a statistical significant difference between them. (Table 1)
Table (1) Comparison between the mean surface microhardness of Group I and Subgroups IIA, IIB and IIC and between different subgroups of group II and their respective subgroups of group III.

\begin{tabular}{|c|c|c|c|}
\hline Groups & Mean \pm SD & t-value & p-value \\
\hline $\begin{array}{c}\text { Group I } \\
\text { Vs }\end{array}$ & $282.2 \pm 28.1$ & 12.8 & $<0.001^{*}$ \\
Subgroup IIA & $156.3 \pm 25.8$ & & \\
\hline $\begin{array}{c}\text { Group I } \\
\text { Vs }\end{array}$ & $282.2 \pm 28.1$ & & \\
Subgroup IIB & $174.3 \pm 20.6$ & & $<0.001^{*}$ \\
\hline $\begin{array}{c}\text { Group I } \\
\text { Vs }\end{array}$ & $282.2 \pm 28.1$ & & \\
Subgroup IIC & $235.3 \pm 26.3$ & 4.7 & $<0.001^{*}$ \\
\hline $\begin{array}{c}\text { Subgroup IIA } \\
\text { Vs }\end{array}$ & $156.3 \pm 25.8$ & & \\
$\begin{array}{c}\text { Subgroup IIIA } \\
\text { Subgroup IIIA }\end{array}$ & $288.8 \pm 15.8$ & 269.6 & $<0.001^{*}$ \\
\hline $\begin{array}{c}\text { Subgroup IIB } \\
\text { Vs }\end{array}$ & $174.3 \pm 20.6$ & & $<0.001^{*}$ \\
\hline $\begin{array}{c}\text { Subgroup IIIB } \\
\text { Subgroup IIIB }\end{array}$ & $267.7 \pm 16.1$ & 242.1 & $<0.001^{*}$ \\
\hline $\begin{array}{c}\text { Subgroup IIC } \\
\text { Vs }\end{array}$ & $235.3 \pm 26.3$ & & $<0.001^{*}$ \\
$\begin{array}{c}\text { Subgroup IIIC } \\
\text { subgroup IIIC }\end{array}$ & $256.2 \pm 22.1$ & 5 & \\
\hline
\end{tabular}

\section{Micro-morphological observation with SEM examination:}

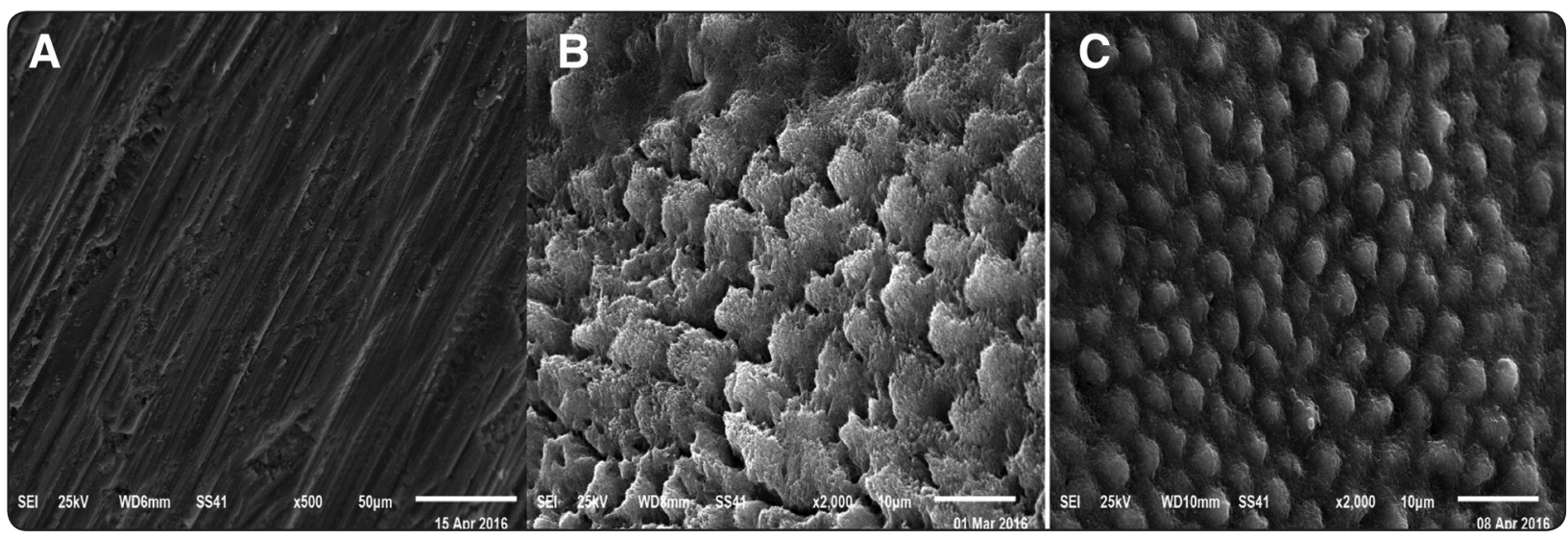

Fig. (1) Representative SEM photomicrographs (x 2000) of surface enamel for (A) Control group, we can see aprismatic layer remnants present on the intact surface. (B) Demineralization group, we can see parallel rows of protruded enamel prisms with interrod space and signs of rod resorption with variations in interrod space. (C) Remineralization group, we can see protruded enamel prisms with head emerging and filling interprismatic spaces. 
III. pH measurement, titratble acidity and buffering capacity:

The $\mathrm{pH}$ value of Farcoline syrup was 5.38 while the titratable acidity was $6.8 \mathrm{~g} / \mathrm{l}$ and the buffering capacity was $1.76 \mathrm{~g} / \mathrm{l}$ x pH. For Farcosolvin syrup the $\mathrm{pH}$ value was 5.06 while the titratable acidity was $4.2 \mathrm{~g} / 1$ and the buffering capacity was $1.05 \mathrm{~g} / \mathrm{l}$ $\mathrm{x} \mathrm{pH}$. Also the $\mathrm{pH}$ value of Heamojet syrup was 5.4 while the titratable acidity was $1.6 \mathrm{~g} / \mathrm{l}$ and the buffering capacity was $0.44 \mathrm{~g} / \mathrm{l}$ x $\mathrm{pH}$.

\section{DISCUSSION}

The present study aimed at the assessment of the "pediatric oral medicines" erosive potential on enamel surface and the remineralization potential of "MI" and "MI Plus" pastes through measuring the surface microhardness and SEM examination.

The degree or severity of erosion cannot be confirmed by "SEM" observations alone. So "SEM" analyses should not be used alone without any quantitative methods as it mainly used to visualize the pathology ${ }^{(16)}$. In the present study the assessment of surface microhardness is a good method to obtain quantitative data. Other studies confirmed such a combined approach for understanding dental erosion ${ }^{(\mathbf{1 8}, \mathbf{1 9})}$.

The in vitro nature of the experimental design of this study and the artificial pattern of exposure to pediatric medicines were applied according to Scatena et al ${ }^{(14)}$ and Xavier et al ${ }^{(17)}$ protocols.

Teeth were stored in $10 \%$ thymol solution as an fungicidal agent until preparation also, in accordance to technical report of the ISO (1999) the storage medium used for the samples was distilled water ${ }^{(\mathbf{2 0})}$, because it simulates the wet oral environment provided by saliva and water, would not promote structural alternation and would be inert also.

In an attempt to remove natural variations in the enamel surface between teeth, a flat and polished specimens were used in this study. However, it should be known that natural tooth surface erode more slowly than polished surfaces ${ }^{(21)}$.

Several pediatric liquid medications may contain components named excipients or "inactive ingredients", which can be deleterious to the dental structures, causing dental caries or erosion. Among these components, the most common are fermentable sugars and acids ${ }^{(22)}$. In the present study, citric acid was found in the composition of the three evaluated medicines, which result in low $\mathrm{pH}$ and produce high levels of erosion, possibly due to its strong chelating properties ${ }^{(23)}$. Also they contain sugars and sweeteners which contraindicates their use by diabetic children and may increase the risk for caries in case of regular use ${ }^{(24)}$.

The following substance features such as titratable acidity "the greater the buffering capacity, the longer it takes saliva to neutralize the acid", calcium chelation properties, adhesion to the dental surface and mineral content have a strong influence in the erosion potential of the substance. So the acid type and $\mathrm{pH}$ value not only the main features that determine a substance erosive potential ${ }^{(23,25)}$.

The total volume of acid in the media ingested as well as the time and frequency of acid exposure influence the erosive potential of an acidic challenge. The commonly prescribed dose of these medicines is $10 \mathrm{~mL}$ taken three times a day so in the present study it was tried to simulate this usually utilized dose. For short erosive challenges " $\mathrm{pH}$ " is the preferred predictor and for erosive potential during longer erosive challenges "titratable acidity" is the preferred predictor as speculated by some authors (26,27). Therefore, in current study, the relationship between erosion of the tooth and the titratable acidity of the syrup may result from the employed long periods of erosive challenges.

Several studies had shown that long-term use of liquid medications led to higher prevalence 
of dental caries in children and as treatment rates increased the severity of carious lesions got worse ${ }^{\text {(28-30) }}$. The utilized syrups in this study were selected because of their routine use in the treatment of common childhood disorders, like "anemia, asthma, bronchitis and cough". So to simulate what would happen over a long treatment the period of the experiment "30 days" was chosen.

It has been extensively researched and proven that the risk of enamel erosion is reduced and remineralization of tooth enamel is promoted when there is a high concentration of "calcium and phosphate" ions in dental plaque ${ }^{(31)}$. At neutral $\mathrm{pH}$ "calcium phosphate" is normally found in insoluble form and forms a crystalline structure. However "calcium" and "phosphate" kept in an amorphous, non-crystalline state by the action of "CPP". In this amorphous state, "calcium" and "phosphate" ions can enter the tooth enamel.

The utilized two remineralizing pastes "MI" and "MI plus" are based on a nano-complex of the milk protein "casein-phosphopeptide" (CPP) with "amorphous calcium phosphate" (ACP) ${ }^{(32)}$ and they were applied on teeth surface twice a day to simulate the recommended daily prophylaxis.

The present study showed that after successive immersion cycles the studied medicines could potentially cause tooth enamel erosion. The mineral loss from enamel surface caused by medicine intake resulted in a decrease in microhardness. The result of the present study showed that there was a highly statistical significant difference between baseline "control group" and after demineralization "medication group". Which reflect the potential erosive effect of the pediatric oral medicines that was used.

This comes in agreement with the studies of Scatena et al ${ }^{(14)}$, Cavalcanti et al ${ }^{(33)}$ and Xavier et $\mathrm{al}^{\left({ }^{17}\right)}$, which revealed that the cariogenic and erosive effect of pediatric drugs and the consumption of medicines potentially harmful to dental tissues. But in contrary to the present study, Bueno et al ${ }^{(34)}$ and Al-shalan ${ }^{(35)}$, found that iron may have cariostatic effect on the in vitro development of dental caries in human teeth also iron capable of interfering with the dissolution of dental enamel in the presence of erosive challenge.

"Salbutamol sulfate" (Farcolin) had the highest value of titratable acidity, which could explain the highest hardness reduction observed in the "salbutamol sulfate" group. "Guaifenesin" (Farcosolvin) had the same buffering capacity as "salbutamol sulfate", but the titratable acidity and buffering capacity of "ferric hydroxide" (Heamojet) is the lowest which could explain the least hardness reduction observed in the "ferric hydroxide" group.

The result of this study showed that there was "no statistical significant difference" of erosion caused by farcolin and farcosolvin but there was a "highly statistical significant difference" of erosion caused by farcolin and farcosolvin and that caused by heamojet. This mean that farcoline and farcosolvin caused mostly the same erosive effect which differs than this caused by heamojet.

Also there is a significant increase in eroded enamel microhardness after using both remineralizing pastes. Which reflect the potential remineralization effect of these pastes on the eroded enamel surface. Also on SEM examination, after topical application of treatment pastes "CPP-ACP" paste (MI) and "CPP-ACPF" paste (MI plus) on eroded enamel specimens it was found that enamel surface had minor tissue dissolution and there is gradual decrease in the porosities of the surface with appearance of mineralized deposits that were scattered along the porous defects.

These result were in agreement with Badr\& Ibrahim (36), who stated that "CPP-ACP" maintain supersaturated levels of bioavailable "calcium and phosphate" ions as it provided a reservoir of 
them, thus inhibits enamel demineralization which explain the protective effect of "CPP-ACP". "CPP" binds to "ACP" through their multiple phosphosryl sequences in metastable solution which prevent "calcium and phosphate" ions dissolution explained by Reynolds\& Walsh ${ }^{(37)}$.

However, the result of this study come inconsistent with Wang et al ${ }^{(32)}$; who investigated the effect of four novel agents including "CPPACP" and "NovaMin" in protection against erosion in an in vitro study. The protective effect of "CPPACP' against erosion did not confirmed in their study, even though in the preliminary experiment the SEM images demonstrated deposit of scattered granular on the tooth surface.

It is likely that $\mathrm{Ca}$ and $\mathrm{P}$ ions co-localized with nanocomplexes as a result of the combination of "CPP-ACP" with "F". The "CPP-ACP" paste was suggested to have high erosive protection potential and this can be attributed to the formation of stabilized "ACPF" phase. This come in agreement with several studies ${ }^{\left({ }^{38}, 39\right)}$ that proved that combined effect of "CPP-ACP" and "F" was beneficial in enhancing remineralization as well as improving acid resisting effect.

The presence of $0.2 \% \mathrm{NaF}$ (900 ppm) with "CPP-ACP" in the "CPP-ACPF" paste would have co-localized $\mathrm{Ca}, \mathrm{P}$ and $\mathrm{F}$ ions at the tooth surface maintaining a state of supersaturation as explained by Cross et al ${ }^{(40)}$.

In Al-Jobiar et al study ${ }^{(41)}$; all tested enamel surface materials including "MI and MI Plus" pastes significantly increased the hardness of eroded enamel when repeatedly applied. MI paste plus (fluoride enriched CPP-ACP) showed better remineralization and higher resistance to erosion when compared to other groups. But Wang et al ${ }^{(32)}$; concluded that "MI" or "MI plus" pastes could not prevent or repair tooth erosion in an in vitro studies.

\section{REFERENCES}

1. Hemingway CA, Parker DM, Addy M, Barbour ME. Erosion of enamel by non-carbonated soft drinks with and without toothbrushing abrasion. British Dental Journal. 2006;201(7):447-50.

2. Lussi A, Hellwig E, Zero D, Jaeggi T. Erosive tooth wear: diagnosis, risk factors and prevention. American journal of dentistry. 2006;19(6):319.

3. Barbour ME, Finke M, Parker DM, Hughes JA, Allen GC, Addy M. The relationship between enamel softening and erosion caused by soft drinks at a range of temperatures. Journal of Dentistry. 2006;34(3):207-13.

4. Yamaguchi K, Miyazaki M, Takamizawa T, Inage H, Moore BK. Effect of CPP-ACP paste on mechanical properties of bovine enamel as determined by an ultrasonic device. Journal of Dentistry. 2006;34(3):230-6.

5. Amaechi BT, Higham SM. In vitro remineralisation of eroded enamel lesions by saliva. Journal of Dentistry. 2001;29(5):371-6.

6. Lussi A, Jaeggi T, Zero D. The Role of Diet in the Aetiology of Dental Erosion. Caries Research. 2004;38(Suppl. 1):34-44.

7. Nunn JH, Ng SK, Sharkey I, Coulthard M. The dental implications of chronic use of acidic medicines in medically compromised children. Pharmacy World and Science. 2001;23(3):118-9.

8. Maguire A, Baqir W, Nunn JH. Are sugars-free medicines more erosive than sugars-containing medicines? An in vitro study of paediatric medicines with prolonged oral clearance used regularly and long-term by children. International Journal of Paediatric Dentistry. 2007;17(4):231-8.

9. Valinoti AC, Da Silva Pierro VS, Da Silva EM, Maia LC. In vitro alterations in dental enamel exposed to acidic medicines. International Journal of Paediatric Dentistry. 2010;21(2):141-50.

10. Ranjitkar S, Rodriguez JM, Kaidonis JA, Richards LC, Townsend GC, Bartlett DW. The effect of casein phosphopeptide-amorphous calcium phosphate on erosive enamel and dentine wear by toothbrush abrasion. Journal of Dentistry. 2009;37(4):250-4.

11. Somasundaram P, Mandke L, Vimala N. Protective potential of casein phosphopeptide amorphous calcium phosphate containing paste on enamel surfaces. Journal of Conservative Dentistry. 2013;16(2):152. 
12. Jayarajan J, Janardhanam P, Jayakumar P, Deepika. Efficacy of CPP-ACP and CPP-ACPF on enamel remineralization - An in vitro study using scanning electron microscope and DIAGNOdent ${ }^{\circledR}$. Indian Journal of Dental Research. 2011;22(1):77.

13. Mehta A, Kumari V, Jose R, Izadikhah V. Remineralization potential of bioactive glass and casein phosphopeptideamorphous calcium phosphate on initial carious lesion: An in-vitro pH-cycling study. Journal of Conservative Dentistry. 2014;17(1):3.

14. Scatena C, Galafassi D, Gomes-Silva JM, Borsatto MC, Serra MC. In Vitro Erosive Effect of Pediatric Medicines on Deciduous Tooth Enamel. Brazilian Dental Journal. 2014;25(1):22-7.

15. Tabrizi A, Cakirer B. A comparative evaluation of casein phosphopeptide-amorphous calcium phosphate and fluoride on the shear bond strength of orthodontic brackets. The European Journal of Orthodontics. 2011;33(3):282-7.

16. Hegazy SA, Awad SM, Shalan HM. Effect of remineralizing solutions on eroded enamel of primary teeth. E.D.J. 2012; 58(1):1-7.

17. Xavier AFC, Moura EFF, Azevedo WF, Vieira FF, Abreu MHNG, Cavalcanti AL. Erosive and cariogenicity potential of pediatric drugs: study of physicochemical parameters. BMC Oral Health. 2013;13(1):71.

18. Sorvari R, Meurman J, Alakuijala P, Frank R. Effect of fluoride varnish and solution on enamel erosion in vitro. Caries Research. 1994;28(4):227-32.

19. Levine R. Briefing paper: Milk, flavoured milk products and caries. British Dental Journal. 2001;191(1):20-2.

20. Titley K, Chernecky R, Rossouw P, Kulkarni G. The effect of various storage methods and media on shear-bond strengths of dental composite resin to bovine dentine. Archives of oral biology. 1998;43(4):305-11.

21. Seow W, Thong K. Erosive effects of common beverages on extracted premolar teeth. Australian Dental Journal. 2005;50(3):173-8.

22. Marquezan M, Marquezan M, Pozzobon R, Oliveira M. Medicines used by pediatric dentistry patients and its cariogenic potential. Rev Pos-Grad. 2007;13:334-9.

23. Lussi A, Jaeggi T. Erosion-diagnosis and risk factors. Clinical oral investigations. 2008;12(1):5-13.
24. Kulkarni M, Sureshkumar C, Venkataramana V. Colourings, flavourings, and sugars in children's medicines in India. BMJ: British Medical Journal. 1993;307(6907):773.

25. Serra MC, Messias DCF, Turssi CP. Control of erosive tooth wear: possibilities and rationale. Braz oral res. 2009; 23.

26. Lussi A, Megert B, Shellis RP, Wang X. Analysis of the erosive effect of different dietary substances and medications. British Journal of Nutrition. 2012;107(02):252-62.

27. Lussi A, Jaeggi T, Schärer S. The influence of different factors on in vitro enamel erosion. Caries research. 1993;27(5):387-93.

28. Passos IA, Sampaio FC, Martínez CR, Freitas CHSdM. Sucrose concentration and $\mathrm{pH}$ in liquid oral pediatric medicines of long-term use for children. Rev Panam Salud Publica. 2010;27(2):132-7.

29. PB S, Raju O. A comparison of oral hygiene status and dental caries in children on long term liquid oral medications to those not administered with such medications. J Indian Soc Pedo Prev Dent. 2002;20(4):144-51.

30. Sunitha S, Prashanth G, Chandu G, Reddy VS. An analysis of concentration of sucrose, endogenous $\mathrm{pH}$, and alteration in the plaque $\mathrm{pH}$ on consumption of commonly used liquid pediatric medicines. Journal of Indian Society of Pedodontics and Preventive Dentistry. 2009;27(1):44.

31. Walsh LJ. Preventive dentistry for the general dental practitioner. Australian Dental Journal. 2000;45(2):76-82.

32. Wang X, Megert B, Hellwig E, Neuhaus K, Lussi A. Preventing erosion with novel agents. Journal of dentistry. 2011;39(2):163-70.

33. Cavalcanti AL, Sousa RI, Clementino MA, Vieira FF, Cavalcanti CL, Xavier AF. In vitro analysis of the cariogenic and erosive potential of paediatric antitussive liquid oral medications. Tanzania journal of health research. 2012; 14(2).

34. Bueno M, Marsicano J, Sales-Peres S. Preventive effect of iron gel with or without fluoride on bovine enamel erosion in vitro. Australian dental journal. 2010;55(2):177-80.

35. Al-Shalan TA. In vitro cariostatic effects of various iron supplements on the initiation of dental caries. The Saudi dental journal. 2009;21(3):117-22.

36. Badr S, Ibrahim MA. Protective effect of three different fluoride pretreatments on artificially induced dental erosion in primary and permanent teeth. J Am Sci. 2010; 6(11):442-51. 
37. Reynolds EC, Walsh LJ. Additional aids to remineralization of tooth structure. In Mount GJ, Hume WR, editors. Preservation and restoration of tooth structure. Sandgate Knowledge Books and Software. 2005:111-8.

38. Holler B, Friedl K-H, Jung H, Hiller K-A, Schmalz G. Fluoride uptake and distribution in enamel and dentin after application of different fluoride solutions. Clinical oral investigations. 2002;6(3):137-44.

39. White A, Gracia L, Barbour M. Inhibition of dental erosion by casein and casein-derived proteins. Caries research.
2010;45(1):13-20

40. Cross K, Huq N, Stanton D, Sum M, Reynolds E. NMR studies of a novel calcium, phosphate and fluoride delivery vehicle- $\alpha$ S1-casein (59-79) by stabilized amorphous calcium fluoride phosphate nanocomplexes. Biomaterials. 2004;25(20):5061-9.

41. Al-Jobair A. The effect of repeated applications of enamel surface treatment on in-vitro bovine enamel hardness after multiple exposures to cola drink. Pakistan Oral \& Dental Journal. 2010;30(1). 